\title{
Body mass index and association with use of and distance from places for physical activity and active leisure among schoolchildren in Brazil. Cross-sectional study
}

\author{
Camila Elizandra Rossi', Elizabeth Nappi Correa", Janaina das Neves"', Cristine Garcia Gabriel" , \\ Jucemar Benedet ${ }^{v}$, Cassiano Ricardo Rech" ${ }^{v 1}$, Francisco de Assis Guedes de Vasconcelos ${ }^{\mathrm{vI}}$ \\ Universidade Federal de Santa Catarina, Florianópolis (SC), Brazil
}

'MSc. Doctoral Student, Universidade Federal de Santa Catarina (UFSC), Florianópolis (SC), Brazil. Dorcid.org/0000-0003-0925-0703

"MD, PhD. Researcher, Department of Nutrition, Universidade Federal de Santa Catarina (UFSC), Florianópolis (SC), Brazil.

Dorcid.org/0000-0002-2863-4262

'"MD, PhD. Researcher, Postgraduate Program on Nutrition, Department of Nutrition, Universidade Federal de Santa Catarina (UFSC),

Florianópolis (SC), Brazil.

Dorcid.org/0000-0002-9026-9841

"MD, PhD. Researcher, Postgraduate Program on Nutrition, Department of Nutrition, Universidade Federal de Santa Catarina (UFSC),

Florianópolis (SC), Brazil.

(Dorcid.org/0000-0002-5413-0826

vMD, PhD. Researcher, Postgraduate Program on Physical Education, Department of Sports, Universidade Federal de Santa Catarina (UFSC),

Florianopolis (SC), Brazil.

(Dorcid.org/0000-0002-2058-6040

"MD, PhD. Researcher, Postgraduate Program on Physical Education, Department of Sports, Universidade Federal de Santa Catarina (UFSC), Florianópolis (SC), Brazil.

Dorcid.org/0000-0002-9647-3448

VIIMD, PhD. Researcher, Postgraduate Program on Nutrition, Universidade Federal de Santa Catarina (UFSC), Florianópolis (SC), Brazil.

Dorcid.org/0000-0002-6162-8067

KEY WORDS:

Environment and public health.

Socioeconomic factors.

Overweight

Youth.

\begin{abstract}
BACKGROUND: We evaluated associations between use of public places for physical activity and active leisure (PAAL) and their distances from subjects' homes and indicators of overweight and obesity, among schoolchildren from different socioeconomic levels, in the city of Florianópolis, Brazil.

DESIGN AND SETTING: Cross-sectional study conducted on a sample of 2,152 schoolchildren aged 7 to 14 years, enrolled at 30 public and private schools.

METHODS: The exposure variables were the use of public places for PAAL in the neighborhood and their distance from schoolchildren's homes. The outcomes were body mass index (BMI) and waist circumference (WC). Univariate and multivariate linear regression analyses were conducted according to income strata. RESULTS: Among the schoolchildren from low-income families, living closer to parks/playgrounds was associated with lower BMI ( $\beta=-2.15 ; 95 \%$ confidence interval, $C I=-2.53 ;-1.77)$ and lower WC $(\beta=-0.11$ $95 \% \mathrm{Cl}=-0.17 ;-0.05)$, while living at these distances from football pitches was associated with higher $\mathrm{BMI}$ $(\beta=1.73 ; 95 \% \mathrm{Cl}=0.31 ; 3.15)$ and larger WC measurements $(\beta=0.03 ; 95 \% \mathrm{Cl}=0.005 ; 0.14)$. Among the schoolchildren in low-income groups, living at an intermediate distance from beaches was associated with lower BMI $(\beta=-1.10 ; 95 \% \mathrm{Cl}=-1.61 ;-0.59)$.

CONCLUSION: Living closer to parks/playgrounds was associated with lower BMI and WC among schoolchildren from low-income families. Living closer to football pitches was associated with higher BMI and WC among these schoolchildren. Living at intermediate distances from beaches was associated with lower BMl among these schoolchildren.
\end{abstract}

\section{INTRODUCTION}

There is evidence showing increasing prevalence of overweight and obesity among children and adolescents in high, medium and low-income countries. ${ }^{1}$ Similar trends were observed in Florianópolis, capital of the Brazilian state of Santa Catarina, during the period from 2002 to 2007, among 7 to 10-year-old children, ${ }^{2}$ and from 2007 to 2012, among 7 to 14-year-old children and adolescents. ${ }^{3}$ In addition, in 2007 and 2008, the prevalence of abdominal obesity among 6 to 10 -year-old schoolchildren in the state of Santa Catarina was observed to be $4.9 \%{ }^{4}$

Studies have shown that the availability of places for physical activity and active leisure (PAAL) close to home makes it more likely that these facilities will be used more often, because of ease of access. ${ }^{5}$ Children and adolescents who report living close to such places tend to have lower body mass index (BMI) and lower values for other measurements of obesity. ${ }^{6,7}$ It has also been indicated in the literature that there are differences in the patterns of usage of neighborhood facilities when different socioeconomic strata are investigated, whether assessed at the family ${ }^{8}$ or area level (the latter based on area of residence). ${ }^{9}$

However, the majority of published studies evaluating individuals of school age have been conducted in high-income countries, located in the northern hemisphere. Consequently, there is a lack of clear evidence regarding associations between measurements of overweight and obesity among children and adolescents living in middle-income and medium-to-high income countries and access to facilities for PAAL in the environs of their homes. ${ }^{5,10,11}$ Another gap in the literature is that the studies have assessed the environmental availability of public spaces in general, without analyzing different types of facilities separately or their relationships with adiposity-related outcomes. ${ }^{6,12-14}$ 
Florianópolis is the capital of the Brazilian state of Santa Catarina, which is located in the country's southern administrative region. In 2016, the municipal district had a population density of 707.4 inhabitants $/ \mathrm{km}^{2}{ }^{15}$ Although the city of Florianópolis has a very high human development index (HDI; 0.847), ${ }^{16}$ it also has an elevated Gini index of 0.5474 (the closer this index is to 1 , the greater the social inequalities between residents are), ${ }^{17}$ which might reflect differences in access to places for PAAL between wealthy and underprivileged areas.

The objective of this study was therefore to investigate associations between use of public places for PAAL, and their distance from subjects' homes, and indicators of overweight and obesity among 7 to 14 -year-old schoolchildren from different socioeconomic levels, in the city of Florianópolis, Brazil.

\section{METHODS}

\section{Ethics}

This study was approved by the Human Research Ethics Committee at the Universidade Federal de Santa Catarina, under review process no. 120,341/2012. The guardians of all schoolchildren selected for the study were sent free and informed consent forms that they needed to sign before the children could be included in the study.

\section{Study design and participants}

This was a cross-sectional study based on a probabilistic sample of 2,506 schoolchildren aged 7-14 years who were enrolled at public or private schools in Florianópolis. The sample was selected by means of clusters, according to: the municipal district's administrative regions; the type of school; the age group; and the number of students enrolled in each school. This procedure aimed to ensure that the sample was representative both of the regions in which the population lives and of the variability of income in the population. The sampling methods have been described in greater detail elsewhere. ${ }^{18,19}$

Based on the prevalence rates of the exposure variables and of each outcome, and considering a study power of $80 \%$, a $95 \%$ confidence level, a 10\% sample size margin to allow for confounding factors and a design effect of 1.8, this study had sufficient power to: a) detect that prevalence ratios of 0.82 to 0.85 would be protective factors and 1.18 to 1.23 would be risk factors for overweight/obesity; and b) detect that prevalence ratios of 0.50 to 0.60 would be protective factors and 1.68 to 2.01 would be risk factors for abdominal obesity.

\section{Data collection}

\section{Study exposure variables}

The schoolchildren were given self-report questionnaires, created for this study, which they and/or their parents/guardians answered. The questions included items asking about the frequency of use of, and perceived distance from home to places for physical activity and active leisure. These were chosen based on findings reported in the scientific literature that discusses these different types of places. ${ }^{20-25}$ Four types of places for PAAL were investigated regarding their frequency of use and perceived distance from home, as follows: beaches, parks/playgrounds, sports courts and football (soccer) pitches. These data were coded as categorical polytomous variables (used weekly, used fortnightly, used monthly, used rarely and never used).

In a nationwide study conducted in Brazil, on 74,589 adolescents aged 12 to 17 years, the subjects who were considered physically active were those for whom the duration of leisure-time physical activity was $\geq 300$ minutes per week. ${ }^{26}$ In this light, and taking into account the possibility that each student might use several places in the vicinity of their homes, the variables of the present study regarding use of places were then re-categorized into two groups: did use them (covering weekly and fortnightly) and did not use them (combining used rarely, used monthly and never used).

The perceived distance from the family home to each type of place was surveyed in terms of the time taken to walk the distance in minutes. The responses were categorized as up to 10 minutes, from 11 to 19 minutes and 20 minutes or more, on the assumption that places that took up to 10 minutes to reach on foot were close to the home (approximately 800 meters) and could therefore be accessed actively, without the need for motorized transportation. ${ }^{27}$

The questionnaire answered by the children and their parents also contained questions on monthly family income and mothers' and fathers' educational levels. The parents' educational levels were classified into three categories (incomplete high school, complete high school, complete higher education). The schoolchildren's ages were analyzed both as a continuous variable and dichotomously in two categories according to the sampling frame applied (7 to 10 or 11 to 14 years of age), and the variable of type of school was divided into two categories (public or private). Monthly family incomes reported in Brazilian reais ( $\mathrm{R} \$$ ) were collected as a continuous variable and were then used to stratify the sample in terciles (high, medium or low-income families), in order to observe whether physical activity environments were associated with the outcome measurements differently for distinct socioeconomic strata. The terciles of monthly income that were used to separate the sample into low, medium and high-income strata were $\mathrm{R} \$<1,577$ (first tercile), $\mathrm{R} \$ 1,577$ to 3,001 (second tercile) and $\mathrm{R} \$>3,001$ (third tercile).

\section{Study outcome variables}

Weight and height data were collected objectively by researchers who had been duly trained in accordance with the technical standards recommended by the World Health Organization 
(WHO). ${ }^{28}$ The absolute intra-examiner technical error of measurement (TEM) that was considered acceptable was twice that of the gold-standard anthropometrist, while the absolute interexaminer TEM that was considered acceptable was three times the experienced anthropometrist's TEM. ${ }^{29}$

$\mathrm{BMI}$, as evaluated according to the WHO criteria, ${ }^{30}$ has shown high sensitivity (92.5\%) for detecting excess body fatness in schoolchildren aged 7-10 years living in Florianópolis. ${ }^{31}$ Hence, we defined overweight as BMI for age and sex $\geq+1$ and $<+2 \mathrm{z}$-scores and obesity as BMI for age and sex $\geq+2 \mathrm{z}$-scores. ${ }^{30}$ In addition, we evaluated waist circumference (WC) in our sample. This measurement was taken at least twice for each schoolchild. These data were used as continuous variables, in $\mathrm{cm}$, in the analyses on associations. WC values were categorized using the criterion for abdominal obesity proposed by Fernandez et al. ${ }^{32}$ (percentile $\geq 90$ for age and sex as the cutoff point) to observe its prevalence in the sample.

\section{Statistical analyses}

Data on the variables of use of places for PAAL and perceived distance from these places were taken to be the primary exposures. Their associations with the two continuous outcome variables BMI (in kilograms divided by meters squared) and WC (in centimeters) were tested using univariate and multivariate linear regression, with estimation of $\beta$ coefficients and $95 \%$ confidence intervals (95\% CI).

Exposure variables with $\mathrm{P}$-values $\leq 0.20$ for univariate associations with outcomes were entered into a multivariate model with forward selection in the order of their strength of association (the higher the P-value was, the earlier the variable was included in the multivariate model). Interactions between the environmental factors and the outcome were tested for sex and age strata first, prior to income stratification, and no differences relating to sex or age strata were observed in these correlations (data not shown).

A 5\% significance level was used for hypothesis testing, considering type I error, and null hypotheses were rejected when the $\mathrm{p}$-value was less than the type I error value. The svy command available in the Stata 13.0 software was used to account for the sample weights of each individual. When multivariate models had been constructed, their goodness of fit was analyzed using the Bartlett test (homogeneity of variance) for qualitative variables. Models were defined as presenting a good fit when they had P-values $>0.05$.

\section{RESULTS}

The study investigated 2,506 schoolchildren. Valid BMI data were obtained from 2,484, and there was at least one valid WC measurement for 2,480. Valid family income data were obtained in relation to 2,152 ( $85.9 \%$ of the sample).

Table 1 lists the characteristics of the whole sample and those of the sample broken down according to family income strata. Overall, the prevalence of overweight was $21.5 \%$ and the prevalence of obesity was $12.7 \%$, thus showing that more than one third of the schoolchildren had excess body weight. Abdominal obesity was detected in $5.0 \%$ of those assessed. There were no significant differences in the mean body mass index or mean waist circumference between the income strata. In relation to the parents' educational level, it was observed that among the schoolchildren from the high-income stratum, more of both the mothers and the fathers had completed undergraduate university education (Table $\mathbf{1}$ ).

The data on the use of each of the different types of public places for PAAL showed that sports courts were the most popular, followed by beaches, parks/playgrounds and, finally, football pitches. Differences in the use of these places according to income strata were observed only in relation to parks/playgrounds, which were used more frequently by schoolchildren in the high-income group. Schoolchildren from the highest income stratum were the ones who most frequently lived closer to football pitches (Table 1).

The frequencies of use of all places for PAAL were significantly and progressively higher when places were near home (Table 2). Multivariate analyses showed that schoolchildren in the low-income group who live at intermediate and closer distances from parks/ playgrounds had lower BMI values $(\beta=-1.96 ; 95 \% \mathrm{CI}=-3.45$; -0.47 ; and $\beta=-2.15 ; 95 \% \mathrm{CI}=-2.53 ;-1.77$, respectively), compared with schoolchildren living far from these facilities. Schoolchildren from the low-income stratum who lived at an intermediate distance from beaches also presented lower values of BMI ( $\beta=-1.10 ; 95 \%$ $\mathrm{CI}=-1.61 ;-0.59$ ). These associations were also observed between higher values of BMI and intermediate and closer distances from football pitches ( $\beta=1.67 ; 95 \% \mathrm{CI}=0.72 ; 2.62$; and $\beta=1.73 ; 95 \%$ $\mathrm{CI}=0.31 ; 3.15$, respectively) (Table 3 ).

Table 4 shows that the same association that was observed between distance from home to parks/playgrounds and BMI was once again present in relation to the $\mathrm{WC}$ of schoolchildren in the low-income group $(\beta=-0.11 ; 95 \% \mathrm{CI}=-0.17 ;-0.05)$. For schoolchildren living 11-19 minutes away from football pitches, an association with WC was also observed $(\beta=0.03 ; 95 \% \mathrm{CI}=0.005 ; 0.14)$.

\section{DISCUSSION}

This study analyzed the use of public places for PAAL and their distances from homes, and their associations with indicators of overweight/obesity among 7 to 14 -year-old schoolchildren living in Florianópolis. The main findings were that associations existed in the stratum of schoolchildren in the low-income group between lower distances from parks/playgrounds and lower BMI and WC values; between lower distances from football pitches and higher BMI and WC values; and between living at an intermediate distance from beaches and lower values of BMI.

With regard to associations between indicators of overweight/ obesity and socioeconomic characteristics, Boing and Subramanian ${ }^{33}$ assessed a population of a different age in Florianópolis. Their study 
enrolled 1,720 adults in 2009 and 2010, and it was observed that the BMI of women living in environments where educational levels were lower was $1.12 \mathrm{~kg} / \mathrm{m}^{2}$ higher than the same index among female residents of areas with high educational levels $(\mathrm{P}<0.05)$. Since the schoolchildren of our sample who were from low-income families had less-educated parents (Table 1), it is reasonable to assume that

Table 1. Descriptive characteristics of the sample of 7 to 14-year-old schoolchildren, stratified according to monthly family income, Florianópolis, Santa Catarina, Brazil, 2012-2013

\begin{tabular}{|c|c|c|c|c|c|c|c|c|c|c|}
\hline \multirow[t]{2}{*}{ Variables } & \multirow[t]{2}{*}{ Categories } & \multicolumn{2}{|c|}{$\begin{array}{c}\text { Total } \\
(n=2,506)\end{array}$} & \multicolumn{2}{|c|}{$\begin{array}{l}\text { Low income } \\
\qquad(n=718)\end{array}$} & \multicolumn{2}{|c|}{$\begin{array}{l}\text { Medium income } \\
\qquad(n=736)\end{array}$} & \multicolumn{2}{|c|}{$\begin{array}{l}\text { High income } \\
\quad(n=698)\end{array}$} & \multirow[t]{2}{*}{ P-value } \\
\hline & & n & $\%$ & n & $\%^{a}$ & n & $\%^{a}$ & n & $\%^{\mathrm{a}}$ & \\
\hline \multirow{2}{*}{ Sex } & Female & 1,334 & 56.5 & 402 & 58.0 & 370 & 54.0 & 362 & 56.7 & \multirow{2}{*}{0.640} \\
\hline & Male & 1,172 & 43.5 & 316 & 42.0 & 366 & 46.0 & 336 & 43.3 & \\
\hline \multirow{2}{*}{ Age (years) } & 7 to 10 & 1,530 & 61.1 & 436 & 61.2 & 473 & 63.9 & 415 & 63.0 & \multirow{2}{*}{0.589} \\
\hline & 11 to 14 & 976 & 38.9 & 282 & 38.8 & 263 & 36.1 & 283 & 37.0 & \\
\hline \multirow{2}{*}{ Type of school } & Public & 1,637 & 65.3 & 672 & 93.9 & 585 & 80.7 & 201 & 26.2 & \multirow{2}{*}{$<0.001$} \\
\hline & Private & 869 & 34.7 & 46 & 6.1 & 151 & 19.3 & 497 & 73.8 & \\
\hline \multirow{3}{*}{ BMI $(n=2,484)$} & (Mean; SD) & 18.60 & 3.55 & 18.72 & 3.80 & 18.74 & 3.71 & 18.44 & 3.24 & 0.616 \\
\hline & Overweight $^{*}$ & 511 & 21.5 & 469 & 65.6 & 473 & 65.6 & 467 & 65.7 & \multirow{2}{*}{0.995} \\
\hline & Obese $^{t}$ & 315 & 12.7 & 241 & 34.4 & 256 & 34.4 & 226 & 34.3 & \\
\hline $\begin{array}{l}\text { Waist circumference } \\
(\mathrm{n}=2,480)\end{array}$ & (Mean; SD) & 61.92 & 8.53 & 61.95 & 3.89 & 61.76 & 3.99 & 62.10 & 3.99 & 0.718 \\
\hline $\begin{array}{l}\text { Abdominal obesity } \\
(n=2,480)\end{array}$ & Yes $^{\ddagger}$ & 134 & 5.0 & 51 & 6.6 & 48 & 5.5 & 25 & 3.7 & 0.198 \\
\hline \multirow{3}{*}{$\begin{array}{l}\text { Mother's educational level } \\
(n=2,389)\end{array}$} & $\begin{array}{l}\text { Incomplete } \\
\text { high school }\end{array}$ & 851 & 33.3 & 443 & 63.5 & 272 & 35.3 & 65 & 7.6 & \multirow{3}{*}{$<0.001$} \\
\hline & $\begin{array}{l}\text { Complete } \\
\text { high school }\end{array}$ & 857 & 37.5 & 210 & 32.5 & 336 & 49.1 & 210 & 32.7 & \\
\hline & $\begin{array}{l}\text { Complete higher } \\
\text { education }\end{array}$ & 681 & 29.2 & 32 & 4.0 & 115 & 15.6 & 416 & 59.7 & \\
\hline \multirow{3}{*}{$\begin{array}{l}\text { Father's educational level } \\
(n=2,086)\end{array}$} & $\begin{array}{l}\text { Incomplete } \\
\text { high school }\end{array}$ & 806 & 35.6 & 364 & 62.6 & 295 & 44.1 & 83 & 11.4 & \multirow{3}{*}{0.002} \\
\hline & $\begin{array}{l}\text { Complete } \\
\text { high school }\end{array}$ & 710 & 35.3 & 144 & 31.0 & 268 & 44.7 & 215 & 30.0 & \\
\hline & $\begin{array}{l}\text { Complete higher } \\
\text { education }\end{array}$ & 570 & 29.1 & 39 & 6.4 & 80 & 11.2 & 343 & 58.6 & \\
\hline \multirow{2}{*}{$\begin{array}{l}\text { Uses beaches } \\
(n=2,382)\end{array}$} & Yes & 745 & 32.9 & 199 & 30.2 & 200 & 26.5 & 223 & 35.7 & \multirow{2}{*}{0.456} \\
\hline & No & 1,637 & 67.1 & 489 & 69.8 & 522 & 73.5 & 462 & 64.3 & \\
\hline \multirow{2}{*}{$\begin{array}{l}\text { Uses parks/ playgrounds } \\
(n=2,342)\end{array}$} & Yes & 642 & 27.5 & 169 & 23.2 & 183 & 24.1 & 205 & 32.6 & \multirow{2}{*}{0.045} \\
\hline & No & 1,700 & 72.5 & 501 & 76.8 & 523 & 75.9 & 476 & 67.4 & \\
\hline \multirow{2}{*}{$\begin{array}{l}\text { Uses sports courts } \\
(\mathrm{n}=2,336)\end{array}$} & Yes & 1,100 & 45.3 & 325 & 47.4 & 322 & 41.3 & 309 & 45.0 & 0288 \\
\hline & No & 1,236 & 54.7 & 345 & 52.6 & 388 & 58.7 & 366 & 55.0 & 0.288 \\
\hline Uses football pitches & Yes & 661 & 25.4 & 209 & 26.1 & 214 & 25.2 & 159 & 23.5 & \\
\hline$(n=2,341)$ & No & 1,680 & 74.6 & 461 & 73.9 & 501 & 74.8 & 517 & 76.5 & 0.836 \\
\hline Distance to parks/ & $1-10$ & 776 & 42.4 & 173 & 31.0 & 221 & 43.7 & 268 & 56.0 & \\
\hline $\begin{array}{l}\text { playgrounds } \\
\text { (minutes) }\end{array}$ & $11-19$ & 419 & 22.9 & 150 & 30.3 & 126 & 19.5 & 103 & 14.3 & 0.101 \\
\hline$(n=1,830)$ & $\geq 20$ & 635 & 34.7 & 178 & 38.7 & 202 & 36.8 & 179 & 29.6 & \\
\hline Distance to sports courts & $1-10$ & 698 & 46.3 & 173 & 39.7 & 207 & 44.4 & 224 & 53.3 & \\
\hline (minutes) & $11-19$ & 372 & 24.6 & 127 & 30.0 & 114 & 20.7 & 92 & 22.2 & 0.132 \\
\hline$(n=1,508)$ & $\geq 20$ & 438 & 29.1 & 117 & 30.3 & 157 & 34.9 & 111 & 24.5 & \\
\hline Distance to football pitches & $1-10$ & 538 & 43.3 & 141 & 35.6 & 172 & 38.3 & 161 & 49.5 & \\
\hline (minutes) & $11-19$ & 306 & 24.6 & 101 & 29.7 & 106 & 31.3 & 71 & 21.1 & 0.002 \\
\hline$(n=1,244)$ & $\geq 20$ & 400 & 32.1 & 123 & 34.7 & 128 & 30.4 & 97 & 29.4 & \\
\hline Distance to beaches & $1-10$ & 476 & 23.0 & 122 & 20.4 & 138 & 21.7 & 144 & 20.9 & \\
\hline (minutes) & $11-19$ & 360 & 17.3 & 109 & 21.3 & 111 & 20.0 & 108 & 17.8 & 0.829 \\
\hline$(n=2,072)$ & $\geq 20$ & 1,236 & 59.7 & 359 & 58.3 & 368 & 58.3 & 368 & 61.3 & \\
\hline
\end{tabular}

$\mathrm{BMI}=$ body mass index; ${ }^{*}$ overweight $95 \% \mathrm{Cl}=16.7-27.3 \%$; ${ }^{\dagger}$ obese $95 \% \mathrm{Cl}=11.0-14.5 \%$; ${ }^{\ddagger}$ abdominal obesity $95 \% \mathrm{Cl}=3.4-7.3 \%$; ${ }^{2}$ percentage values take into account the design effect (svy command); ${ }^{b}$ p-value significant at $5 \%$ for Pearson's chi-square test. 
Table 2. Frequency of schoolchildren using places for PAAL according to perceived distances from the places to home. Florianópolis, Santa Catarina, Brazil, 2012-2013

\begin{tabular}{|c|c|c|c|c|c|c|c|}
\hline \multirow{3}{*}{$\begin{array}{l}\text { Frequency of use of places for PAAL } \\
\text { Uses beaches }(n=2,069)\end{array}$} & \multicolumn{6}{|c|}{ Perceived distance from home in time walking (minutes) } & \multirow{3}{*}{ P-value* } \\
\hline & \multicolumn{2}{|c|}{$1-10$} & \multicolumn{2}{|c|}{$11-20$} & \multicolumn{2}{|c|}{$>21$} & \\
\hline & $\mathrm{n}$ & $\%$ & $\mathrm{n}$ & $\%$ & $\mathrm{n}$ & $\%$ & \\
\hline Yes & 300 & 67.2 & 150 & 42.6 & 277 & 23.2 & $<0.000$ \\
\hline \multicolumn{8}{|l|}{ Uses parks/ playgrounds $(n=1,826)$} \\
\hline Yes & 378 & 48.1 & 139 & 32.6 & 114 & 16.2 & $<0.000$ \\
\hline Yes & 538 & 75.4 & 257 & 68.2 & 232 & 50.9 & \multirow{2}{*}{$<0.000$} \\
\hline No & 159 & 24.6 & 113 & 31.8 & 206 & 49.1 & \\
\hline \multicolumn{8}{|l|}{ Uses football pitches ( $n=1,237$ ) } \\
\hline Yes & 326 & 59.4 & 160 & 49.1 & 147 & 36.0 & \multirow{2}{*}{$<0.000$} \\
\hline No & 208 & 40.6 & 145 & 50.9 & 251 & 64.0 & \\
\hline
\end{tabular}

*Tendency from chi-square test.

Table 3. Crude and adjusted analyses on association between use of public places for physical activity and their distances from homes and body mass index, according to family income strata, among 7 to 14-year-old schoolchildren living in Florianópolis, Santa Catarina, Brazil, $2012-2013$

\begin{tabular}{|c|c|c|c|c|c|c|c|c|c|c|c|c|}
\hline \multirow{3}{*}{$\begin{array}{l}\text { Environmental } \\
\text { variables }\end{array}$} & \multicolumn{4}{|c|}{ Low income } & \multicolumn{4}{|c|}{ Medium income } & \multicolumn{4}{|c|}{ High income } \\
\hline & \multicolumn{2}{|c|}{ Crude analyses $^{\mathrm{a}}$} & \multicolumn{2}{|c|}{$\begin{array}{c}\text { Adjusted } \\
\text { analyses, } *, a, b\end{array}$} & \multicolumn{2}{|c|}{ Crude analyses $^{\mathrm{a}}$} & \multicolumn{2}{|c|}{$\begin{array}{c}\text { Adjusted } \\
\text { analyses }\end{array}$} & \multicolumn{2}{|c|}{ Crude analyses $^{\mathrm{a}}$} & \multicolumn{2}{|c|}{$\begin{array}{l}\text { Adjusted } \\
\text { analyses }\end{array}$} \\
\hline & $\beta$ & $95 \% \mathrm{Cl}$ & $\beta$ & $95 \% \mathrm{Cl}$ & $\beta$ & $95 \% \mathrm{Cl}$ & $\beta$ & $95 \% \mathrm{Cl}$ & $\beta$ & $95 \% \mathrm{Cl}$ & $\beta$ & $95 \% \mathrm{Cl}$ \\
\hline No & 0.00 & & - & - & 0.00 & & 0.00 & & 0.00 & & 0.00 & \\
\hline Yes & -0.01 & $-0.71 ; 0.69$ & - & - & 0.25 & $-0.44 ; 0.95$ & 0.21 & $-1.11 ; 1.53$ & -0.33 & $-0.55 ;-0.09$ & -0.10 & $-1.69 ; 1.49$ \\
\hline \multicolumn{13}{|c|}{ Uses parks/ playgrounds } \\
\hline Yes & -0.39 & $-1.12 ; 0.32$ & 0.61 & $-0.79 ; 2.00$ & -0.45 & $-1.67 ; 0.77$ & -0.45 & $-2.01 ; 1.10$ & -0.56 & $-2.52 ; 1.40$ & - & - \\
\hline \multicolumn{13}{|c|}{ Uses sports courts } \\
\hline No & 0.00 & & 0.00 & & 0.00 & & 0.00 & & 0.00 & & 0.00 & \\
\hline Yes & 0.58 & $-0.23 ; 1.40$ & 0.79 & $-1.41 ; 2.99$ & 0.008 & $-0.94 ; 0.96$ & -0.44 & $-2.32 ; 1.43$ & 0.88 & $-0.58 ; 2.34$ & 0.08 & $-3.23 ; 3.39$ \\
\hline \multicolumn{13}{|c|}{ Uses football pitches } \\
\hline $1-10$ & 1.08 & $-0.49 ; 2.67$ & 0.94 & $-1.92 ; 3.80$ & -0.25 & $-0.59 ; 0.08$ & -0.65 & $-1.60 ; 0.31$ & 0.13 & $-0.11 ; 0.38$ & - & - \\
\hline $11-19$ & -0.02 & $-1.31 ; 1.26$ & -1.10 & $-1.61 ;-0.59$ & -0.58 & $-2.05 ; 0.89$ & -0.81 & $-2.36 ; 0.75$ & -0.14 & $-1.50 ; 1.22$ & - & - \\
\hline$\geq 20$ & 0.00 & & 0.00 & & 0.00 & & 0.00 & & 0.00 & & - & - \\
\hline \multicolumn{13}{|c|}{ Distance to parks/playgrounds (minutes) } \\
\hline $1-10$ & -0.77 & $-1.92 ; 0.38$ & -2.15 & $-2.53 ;-1.77$ & -0.46 & $-1.65 ; 0.73$ & - & - & 0.78 & $0.44 ; 1.12$ & 1.11 & $-0.12 ; 2.34$ \\
\hline $11-19$ & -1.52 & $-3.29 ; 0.24$ & -1.96 & $-3.45 ;-0.47$ & 0.10 & $-1.36 ; 1.56$ & - & - & 0.86 & $-1.00 ; 2.72$ & 0.07 & $-1.20 ; 1.35$ \\
\hline$\geq 20$ & 0.00 & & 0.00 & - & 0.00 & & - & - & 0.00 & & 0.00 & \\
\hline \multicolumn{13}{|c|}{ Distance to sports courts (minutes) } \\
\hline $1-10$ & 0.93 & $-0.85 ; 2.71$ & - & - & 0.06 & $-1.11 ; 1.23$ & 0.41 & $-0.40 ; 1.23$ & 0.10 & $-2.05 ; 2.27$ & - & - \\
\hline $11-19$ & 0.34 & $-2.00 ; 2.69$ & - & - & 0.02 & $-1.42 ; 1.46$ & 0.13 & $-1.31 ; 1.55$ & -0.11 & $-3.43 ; 3.21$ & - & - \\
\hline
\end{tabular}

*Multivariate models were controlled for the continuous variable of schoolchildren's age; ap-value significant at 5\%; 'bariables of use of and distance from football pitches presented collinearity. 
these schoolchildren from low-income families also lived in areas where incomes and educational levels were lower, thus raising the hypothesis that other variables relating to inequalities in the economic environment (such as availability of safe places for physical activity and existence of pedestrian-friendly environments in residential areas ${ }^{9,34}$ ) may be mediating overweight/obesity. Similar results have also been observed in other countries, albeit high-income countries. Lakes and Burkart ${ }^{35}$ assessed 28,159 children aged 5 to 6 years who were living in Berlin and observed that an increase of one point (on a scale from 4 to 8 ) in a family's social index (relating to socioeconomic level) resulted in a $68.5 \%$ reduction in overweight.

Concerning the proximity of homes to parks/playgrounds and the association of this factor with both outcomes in the low-income family stratum, Hsieh et al. ${ }^{36}$ assessed Hispanic girls in Los Angeles, United States, who would be expected to have lower incomes than non-Hispanic residents. They found that the level of body fat was $1.4 \%$ lower among those who lived in neighborhoods with more than three acres of space reserved for parks. The higher density of parks around adolescents' schools in Taiwan was also associated with lower values for waist circumference among boys. ${ }^{37}$

In relation to the association between intermediate distance from beaches to homes and lower BMI, Abbot et al. ${ }^{38}$ found similar results among 1,819 women (aged 18-66) living in Melbourne, Australia. The presence of a coastline within $2 \mathrm{~km}$ of less educated women's homes explained $10.1 \%$ of the education-BMI relationship. These results suggest that beaches are also a good option for exercise, even among children and adults from low-income families.

In contrast with what was observed for parks/playgrounds, use of football pitches had a positive relationship with BMI and WC among low-income schoolchildren. These findings suggest reverse causality, thus indicating that low-income schoolchildren who have abdominal obesity use these places to exercise more. In fact, in Córdoba (Argentina) Lavin-Fueyo and Berra ${ }^{39}$ observed that

Table 4. Crude and adjusted analysis on association between use of public places for physical activity and their distances from homes and waist circumference, according to family income strata, among 7 to 14-year-old schoolchildren living in Florianópolis, Santa Catarina, Brazil, $2012-2013$

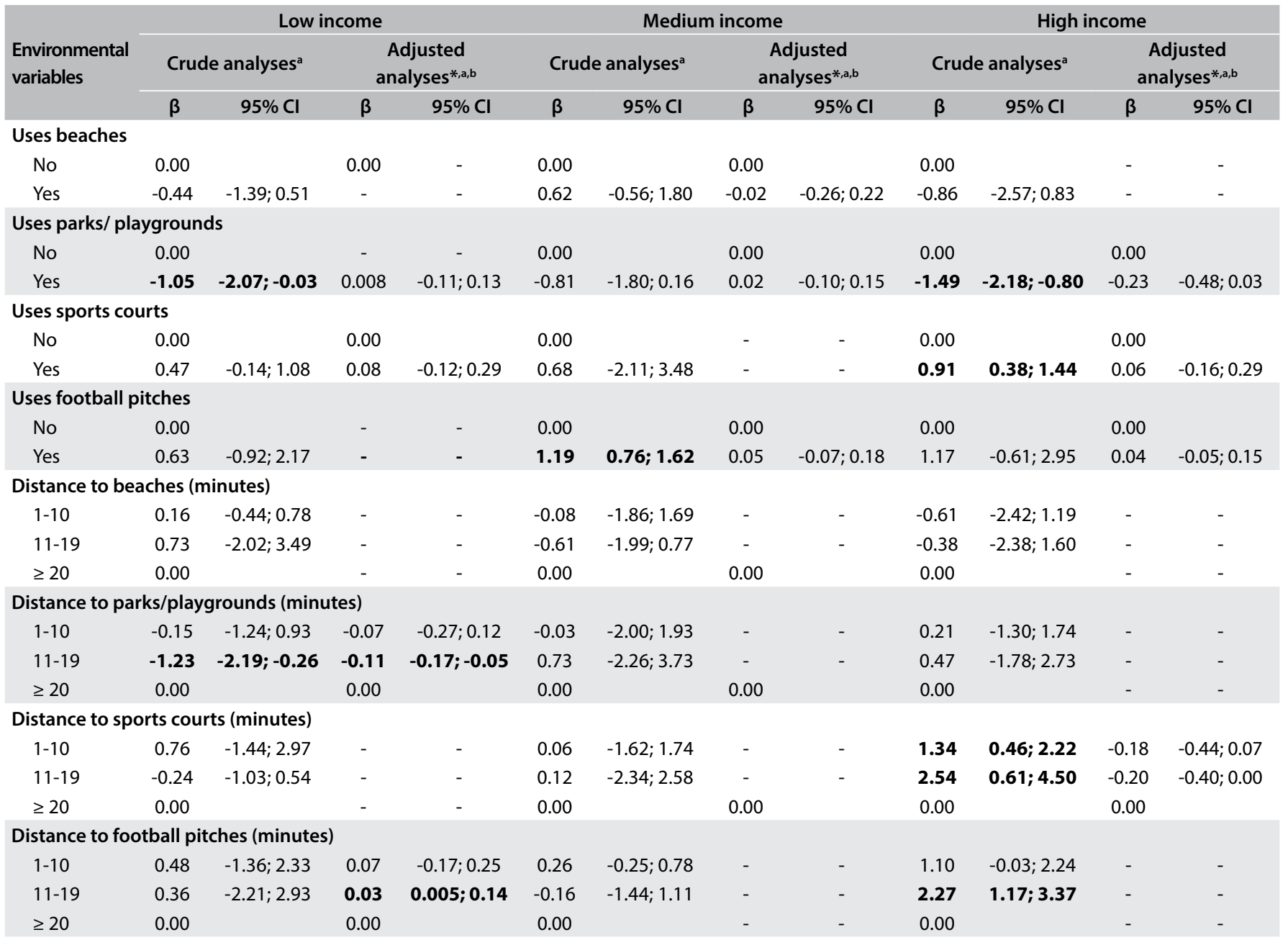

*Multivariate models were controlled for the continuous variable of schoolchildren's age; ap-value significant at 5\%; 'variables of use of and distance from football pitches presented collinearity. 
the places for physical activity that schoolchildren from peripheral underprivileged neighborhoods used most were parks/public squares, in the first place, followed by football pitches. Another reason why we found a positive relationship between these variables could be that children and adolescent habitually go to football pitches to watch games, and this does not contribute towards improving their energy expenditure.

In our study, in the medium and higher-income strata, none of the environmental variables were associated with the outcomes in the adjusted analyses. One possible explanation for this is that in this socioeconomic stratum, other physical activity options, especially those that are supervised and consequently are not free of charge, may be used instead of public options. Bürgi et al. ${ }^{9}$ in Zurich, Switzerland, observed that children living in neighborhoods with higher socioeconomic status did the majority of their moderate to intense physical activities in schools other than their own, possibly through taking part in paid-for exercise options.

It is also interesting to note that even though the variable of the distance from places for physical activity was associated with both outcomes, the variable of "use" of the same type of places was not statistically significant in any of the income strata in our study. In our sample, we found a significant positive relationship between frequency of use of places and their proximity to schoolchildren's homes (Table 2). Lavin-Fueyo et al. ${ }^{40}$ used the same approach as in our study, to investigate the use of these places and their distances from homes. They investigated 1,777 children aged 9 to 11 years in the city of Córdoba, Argentina, in 2011, and also found that use of parks was associated with their proximity to schoolchildren's homes but was not associated with increases in the amount of physical activity. Among 22,889 adults evaluated in neighborhoods of Yorkshire, England, greater availability of parks within a distance of $2 \mathrm{~km}$ from home were associated both with lower BMI values and with lower prevalence of obesity. ${ }^{41}$ In Louisiana, United States, the body profile of 909 women and their children was evaluated and it was found that living in a neighborhood with less provision of parks, playgrounds and other recreational places was significantly associated both with higher BMI and with larger WC, after adjusting for covariates. ${ }^{42}$ These findings might indicate that the use of public spaces and open places for physical activities would be more frequent if these places are closer to home, and that maybe it is necessary to use them aiming to practice non-sedentary activities more than once a week, for there to be any positive effects regarding the intensity of physical activity and consequently regarding body profile. Such results are shown more frequently in adulthood.

The present study indicates that future analyses on the influence of the environment on physical activity and active leisure among children and adolescents living in medium-to-high income countries such as Brazil should take into account the economic inequalities affecting these populations, both at the family and at the environmental level. One strong point of the present study is the fact that the sample was probabilistic and randomized, with a sample that was representative of schools in all five geographi$\mathrm{cal}$ regions in the municipal district studied. The weighting effect of each person in the sample was also taken into account (svy command), which minimized bias in the analysis on variables for which there were fewer responses. Interactions between the environmental variables were also analyzed (chi-square analyses), which reduced bias due to collinearity in multivariate models (we found collinearity between the variables of use of football pitches and distance from home to these places).

The primary limitation of this study was its cross-sectional design, which means that additional evidence is needed to support the findings. In addition, our study may have been affected by a cause-effect relationship among the variables, such that some schoolchildren who were using places for physical activity may have been doing so as part of a treatment for obesity. A situation of this nature would possibly hide a previously existing association with high body mass index and high measurements of waist circumference. Furthermore, we did not assess data on physical activity levels and food intake, because several variables could not be properly fitted into the multivariate models. Moreover, the correlation between the self-reported measurements of distances from schoolchildren's homes to the places with exercise facilities and objective measurements may not have been good. In such a situation, further studies regarding the feasibility of self-reported measurements for this issue would be required.

Our data indicate that there is a need to evaluate the relationship between the proximity of homes to places for PAAL and measurements of adiposity among the schoolchildren of Florianópolis in longitudinal studies, in order to confirm whether there is any direct relationship between the variables. If the findings from the present study are confirmed, it can be recommended that the public authorities responsible for urban planning of municipal districts should consider the need for creation of free public places for PAAL, especially in economically underprivileged areas, in order to encourage active behavior among their residents and prevent the emergence of overweight and obesity among children and adolescents in low-income groups.

\section{CONCLUSION}

This study identified a significant association between proximity of parks/playgrounds to homes and lower BMI and WC values, and an association between short distances from homes to football pitches and higher BMI and WC among schoolchildren in low-income groups who were living in Florianópolis. An intermediate distance from homes to beaches was also associated with lower BMI values among schoolchildren from lowincome families. 


\section{REFERENCES}

1. Lobstein T, Jackson-Leach R, Moodie ML, et al. Child and adolescent obesity: part of a bigger picture. Lancet. 2015;385(9986):2510-20. doi: 10.1016/S0140-6736(14)61746-3.

2. Leal DB, de Assis MA, González-Chica DA, da Costa FF. Trends in adiposity in Brazilian 7-10-year-old schoolchildren: evidence for increasing overweight but not obesity between 2002 and 2007. Ann Hum Biol. 2014 May-Jun;41 (3):255-62. doi: 10.3109/03014460.2013.854832.

3. Motter AF, Vasconcelos F de A, Correa EN, Andrade DF. Pontos de venda de alimentos e associação com sobrepeso/obesidade em escolares de Florianópolis, Santa Catarina, Brasil [Retail food outlets and the association with overweight/obesity in schoolchildren from Florianópolis, Santa Catarina State, Brazil]. Cad Saúde Pública. 2015;31(3):620-32. http://dx.doi.org/10.1590/0102-311x00097814.

4. Feltrin GB, Vasconcelos FAG, Costa LCF, Corso ACT. Prevalence and factors associated with central obesity in schoolchildren in Santa Catarina, Brazil. Rev Nutr. 2015;28(1):43-54. PMID: 25859728.

5. Feng J,Glass TA, Curriero FC, StewartWF, Schwartz BS. The builtenvironment and obesity: a systematic review of the epidemiologic evidence. Health Place. 2010;16(2):175-90. doi: 10.1016/j.healthplace.2009.09.008.

6. Wasserman JA, Suminski R, Xi J, et al. A multi-level analysis showing associations between school neighborhood and child body mass index. Intern J Obes (Lond). 2014;38(7):912-8. doi: 10.1038/ijo.2014.64.

7. Jones A. Residential instability and obesity over time: the role of the social and built environment. Health Place. 2015;32:74-82. doi: 10.1016/j. healthplace.2015.01.001.

8. Roe J, Aspinall PA, Ward Thompson C. Understanding Relationships between Health, Ethnicity, Place and the Role of Urban Green Space in Deprived Urban Communities. Int J Environ Res Public Health. 2016;13(7). pii: E681. doi: 10.3390/ijerph13070681.

9. Bürgi R, Tomatis L, Murer K, de Bruin ED. Spatial physical activity patterns among primary school children living in neighbourhoods of varying socioeconomic status: a cross-sectional study using accelerometry and Global Positioning System. BMC Public Health. 2016;16:282. doi: 10.1186/s12889-016-2954-8.

10. Williams J, Scarborough P, Matthews A, et al. A systematic review of the influence of the retail food environment around schools on obesityrelated outcomes. Obes Rev. 2014;15(5):359-74. doi: 10.1111/obr.12142.

11. MayneSL,Auchincloss AH,MichaelYL. Impact of policy and builtenvironment changes on obesity-related outcomes: a systematic review of naturally occurring experiments. Obes Rev. 2015;16(5):362-75. doi: 10.1111/obr.12269.

12. Edwards KL, Clarke GP, Ransley JK, Cade J. The neighbourhood matters: studying exposures relevant to childhood obesity and the policy implications in Leeds, UK. J Epidemiol Community Health. 2010;64(3):194-201. doi: 10.1136/jech.2009.088906.

13. Duncan DT, Sharifi M, Melly SJ, et al. Characteristics of walkable built environments and BMI z-scores in children: evidence from a large electronic health record database. Environ Health Perspec. 2014;122:1359-65. doi: 10.1136/jech.2009.088906.
14. Buck C, Kneib T, TkaczickT, Konstabel K, Pigeot I. Assessing opportunities for physical activity in the built environment of children: interrelation between kernel density and neighborhood scale. Int J Health Geogr. 2015;14:35. doi: 10.1186/s12942-015-0027-3.

15. IBGE. Cidades. Santa Catarina. Florianópolis. Available from: http:// cidades.ibge.gov.br/xtras/perfil.php?lang=\&codmun=420540\&searc h=santa-catarina|Florianópolis. Accessed in 2018 (Feb 5).

16. Programa das Nações Unidas para o Desenvolvimento - PNUD, Instituto de Pesquisa Econômica Aplicada - Ipea, Fundação João Pinheiro. O Índice de Desenvolvimento Humano Municipal Brasileiro. Brasília: PNUD, Ipea, FJP; 2013.

17. Brasil, Ministério da Saúde. Indicadores socioeconômicos. Índice de Gini da renda domiciliar per capita. Available from: http://tabnet.datasus. gov.br/cgi/idb2011/b09capc.htm. Accessed in 2017 (Dec 26).

18. Corrêa EN, Rossi CE, das Neves J, Silva DA, Vasconcelos FA. Utilization and environmental availability of food outlets and overweight/obesity among schoolchildren in a city in the south of Brazil. J Public Health (Oxf). 2017:1-8. doi: 10.1093/pubmed/fdx017.

19. Pinho MGM, Adami F, Benedet J, Vasconcelos FAG. Associação entre tempo de tela e padrões alimentares com sobrepeso/obesidade em adolescentes [Association between screen time and dietary patterns and overweight/obesity among adolescents]. Rev Nutr. 2017;30(3):37789. doi: 10.1590/1678-98652017000300010.

20. Jago R, Baranowski T, Baranowski JC, Cullen KW, Thompson D. Distance to food stores \& adolescent male fruit and vegetable consumption: mediation effects. Intern J Behav Nutr Phys Activ. 2007;4:35. doi: 10.1186/1479-5868-4-35.

21. Jilcott SB, Wade S, McGuirt JT, et al. The association between the food environment and weight status among eastern North Carolina youth. Public Health Nutr. 2011;14(9):1610-7. doi: 10.1017/S1368980011000668.

22. Black JL, Day M. Availability of limited service food outlets surrounding schools in British Columbia. Can J Public Health. 2012;103(4):e255-9. PMID: 23618636.

23. He M, Tucker P, Gilliland J, et al. The influence of local food environments on adolescents'food purchasing behaviors. Intern J Environ Res Public Health. 2012;9(4):1458-71. doi: 10.3390/ijerph9041458.

24. Jáuregui A, Salvo D, Lamadrid-Figueroa $H$, et al. Perceived and Objective Measures of Neighborhood Environment for Physical Activity Among Mexican Adults, 2011. Prev Chronic Dis. 2016;13:E76. doi: 10.5888/ pcd13.160009.

25. Dewulf B, Neutens T, Van Dyck D, de Bourdeaudhuij I, Van de Weghe $\mathrm{N}$. Correspondence between objective and perceived walking times to urban destinations: Influence of physical activity, neighbourhood walkability, and socio-demographics. Int J Health Geogr. 2012;11: 43. doi: 10.1186/1476-072X-11-43.

26. Cureau FV, da Silva TL, Bloch KV, et al. ERICA: inatividade física no lazer em adolescentes brasileiros [ERICA: leisure-time physical inactivity in Brazilian adolescents]. Rev Saúde Pública. 2016;50 Suppl 1:4s. doi: 10.1590/S01518-8787.2016050006683. 
27. Colabianchi N, Dowda M, Pfeiffer KA, et al. Towards an understanding of salient neighborhood boundaries: adolescent reports of an easy walking distance and convenient driving distance. Int J Behav Nutr Phys Act. 2007;4:66. doi: 10.1186/1479-5868-4-66.

28. World Health Organization/WHO. Physical status: the use and interpretation of anthropometry. WHOTechnical Report Series, 854. Geneva: World Health Organization; 1995. Available from: http://www.who.int/childgrowth/ publications/physical_status/en/. Accessed in 2017 (Dec 26).

29. Habicht J. Estandarización de métodos epidemiológicos cuantitativos sobre el terreno [Standardization of quantitative epidemiological methods in the field]. Bol Oficina Sanit Panam. 1974;76(5):375-84. PMID: 4277063.

30. de Onis ML, Onyango AW, Borghi E, et al. Development of a WHO growth reference for school-aged children and adolescents. Bull World Health Org. 2007;85(9):660-7. PMID: 18026621.

31. Leal DB, De Assis MAA, Conde WL, Bellisle F. Desempenho de referências baseadas no índice de massa corporal para a detecção do excesso de gordura corporal em escolares de 7 a 10 anos de idade [Performance of references based on body mass index for detecting excess body fatness in schoolchildren aged 7 to 10 years]. Rev Bras Epidemiol. 2014;17(2):517-30. doi: 10.1590/1809-4503201400020017ENG.

32. Fernández JR, Redden DT, Pietrobelli A, Allison DB. Waist circumference percentiles in nationally representative samples of African-American, European-American, and Mexican-American children and adolescents. J Pediatr. 2004;145(4):439-44. doi: 10.1016/j.jpeds.2004.06.044.

33. Boing AF, Subramanian SV. The influence of area-level education on body mass index, waist circumference and obesity according to gender. Int J Public Health. 2015;60(6):727-36. doi: 10.1007/s00038-015-0721-8.

34. Powell-Wiley TM, Moore K, Allen N, et al. Associations of neighborhood crime and safety with changes in body mass index and waist circumference: the Multi-Ethnic Study of Atherosclerosis. Amer J Epidem. 2017;186(3):280-8. doi: 10.1093/aje/kwx082.

35. Lakes T, Burkart K. Childhood overweight in Berlin: intra-urban differences and underlying influencing factors. Int J Health Geogr. 2016;15:12. doi: 10.1186/s12942-016-0041-0.

36. Hsieh S, Klassen AC, Curriero FC, et al. Built environment associations with adiposity parameters among overweight and obese Hispanic youth. Prev Med Rep. 2015;2:406-12. doi: 10.1016/j.pmedr.2015.05.005.

37. Chiang PH, Huang LY, Lee MS, Tsou HC, Wahlqvist ML. Fitness and food environments around junior high schools in Taiwan and their association with body composition: gender differences for recreational, reading, food and beverage exposures. PLoS One. 2017;12(8):e0182517. doi: 10.1371/journal.pone.0182517.

38. Abbott G, Backholer K, Peeters A, et al. Explaining educational disparities in adiposity: the role of neighborhood environments. Obesity (Silver Spring). 2014;22(11):2413-9. doi: 10.1002/oby.20853.

39. Lavin-Fueyo J, Berra S. Places children use for physical activity in peripheral neighborhoods of the city of Cordoba. Salud Colect. 2015;11(2):223-34. doi: 10.1590/S1851-82652015000200006.
40. Lavin Fueyo J, Totaro Garcia LM, Mamondi V, et al. Neighborhood and family perceived environments associated with children's physical activity and body mass index. Prev Med. 2016;82:35-41. doi: 10.1016/j. ypmed.2015.11.005.

41. Hobbs M, Griffiths C, Green MA, et al. Neighbourhood typologies and associations with body mass index and obesity: A cross-sectional study. Prev Med. 2017 Dec 2. pii: S0091-7435(17)30465-6. doi: 10.1016/j. ypmed.2017.11.024.

42. Sullivan SM, Peters ES, Trapido EJ, et al. Assessing mediation of behavioral and stress pathways in the association between neighborhood environments and obesity outcomes. Prev Med Reports. 2016; 4:24855. doi: 10.1016/j.pmedr.2016.06.012.

Acknowledgements: The authors are grateful to the National Council for Scientific and Technological Development (Conselho Nacional de Desenvolvimento Científico e Tecnológico, CNPq) (MCTI/CNPq no. 014/2011; CNPq no. 483955/2011-6), to the Postgraduate Program on Nutrition of the Federal University of Santa Catarina and to the Coordination Office for Improvement of Higher-Education Personnel (Coordenação de Aperfeiçoamento de Pessoal de Nível Superior, (APES), for their financial support. CER also received a research grant from the Research and Innovation Support Foundation of the State of Santa Catarina (Fundação de Apoio à Pesquisa e Inovação do Estado de Santa Catarina, FAPESC)

Sources of funding: Conselho Nacional de Desenvolvimento Científico e Tecnológico (CNPq; grant number 483955/2011-6) and a bursary from Fundação de Apoio à Pesquisa e Inovação do Estado de Santa Catarina (FAPESC; grant number 10/2013)

\section{Conflict of interest: None}

Date of first submission: November 2, 2017

Last received: December 25, 2017

Accepted: January 2, 2018

\author{
Address for correspondence: \\ Camila Elizandra Rossi \\ Programa de Pós-Graduação em Nutrição, Universidade Federal \\ de Santa Catarina \\ Centro de Ciências da Saúde \\ Trindade — Florianópolis (SC) — Brasil \\ CEP 88040-900 \\ Tel. (+55 48) 3721-9784 \\ E-mail: camilarossi@uffs.edu.br
}

